\title{
The Management of Financial Supply Chains: From Adversarial to Co-operative Strategies
}

\author{
Ian D. Blackman, Christopher Holland \\ Ian D. Blackman: \\ School of Information Systems, Computing and Mathematics, Brunel \\ University, Uxbridge St John's Building, Uxbridge, UB8 3PH, UK \\ ian.blackman@brunel.ac.uk \\ Christopher Holland: \\ Manchester Business School, The University of Manchester, Booth Street \\ West, Manchester, M15 6PB, UK \\ Chris.holland@mbs.ac.uk
}

\begin{abstract}
Information systems have developed along the supply chain to support logistics management in all types of industries. Most of this effort has been focused at reducing the levels of working capital by increasing the efficiency of information flow from market to raw materials suppliers. Similar developments have also occurred to support other business processes, for example connecting together new product design and marketing databases to create virtual corporations. Electronic commerce and associated technologies such as EDI are the norm in advanced supply chains and it is common for their use to be mandatory when trading with large companies. The manufacturing of a product is now seen as a whole process across the supply chain rather than a series of separate operations managed and controlled by different organisations. The management of logistics has been fundamentally re-engineered and designed to focus on quality and time-based strategies. However developments in the handling of financial information between functions within companies and across organisational boundaries have lagged far behind the developments in logistics management. This paper explores the potential benefits of cooperative relationships in the financial supply chain to reduce the time delays and increase the level of certainty regarding financial transactions between separate organisations. The financial benefits are estimated using published data to provide a potential saving of $3.8 \%$ of the value of the transaction. An organizational model is presented of likely future developments and steps that can be taken by the financial
\end{abstract}


service industry to benefit as integrated providers of financial services to supply chains and the areas for initial implementation are outlined.

\section{Introduction - Integration of the Physical Supply Chain}

The development of supply chains has been one of the major recent organizational phenomena that have been enabled by modern information and communication technologies $[1,2]$. Large corporations have made significant progress in linking their information systems to share data with trading partners and there has been an enormous increase in the use of electronic commerce leading to its almost mandatory use for certain industries $[3,4)$. E-commerce has been used mainly to improve the logistics of the supply chain by shortening lead times to satisfy customer orders and reduce the stocks held in the supply chain. The direct transfer of the order information between organisations within integrated supply chains ensures trading partners are certain of the date and time of delivery of supplies enabling a reduction in working capital (see Figure One).

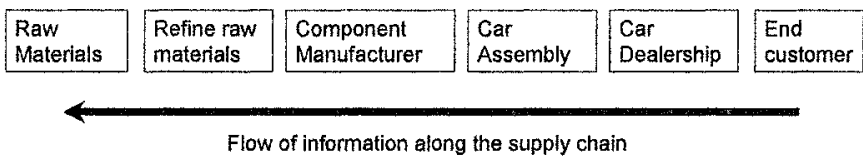

Fig.1. Certain flow of information through the physical supply chain

The market demands for improved manufacturing quality and responsive supply chains have forced companies to co-operate within the supply chain. Closer relationships with individual suppliers are necessary to ensure that components meet the exacting requirements of the end customer and product development cycles can be reduced to meet changes in market demands. The greater reliance on a smaller group of suppliers has enabled the rigorous implementation of Just-In-Time (JIT) strategies and associated quality processes [5]. The improvement in quality is a continuous process and is enabled by information systems which make errors 
immediately apparent. Similarly the removal of buffer stocks means that production is halted if there is any delay to JIT deliveries or quality problems emerge.

This paper proposes a theoretical model which explores the potential benefits of using inter-connected information systems to link financial information along the supply chain. It describes how the financial risk and transaction costs between separate organisations can be minimised. This is achieved by the finance function adopting lessons learnt from logistics management. One implication is that the finance function must be integrated more closely with other organisational functions and also with the finance functions of trading partners. The roles of the partners are analysed and barriers to implementation discussed.

\section{Uncertain transfer of information along the Financial Supply}

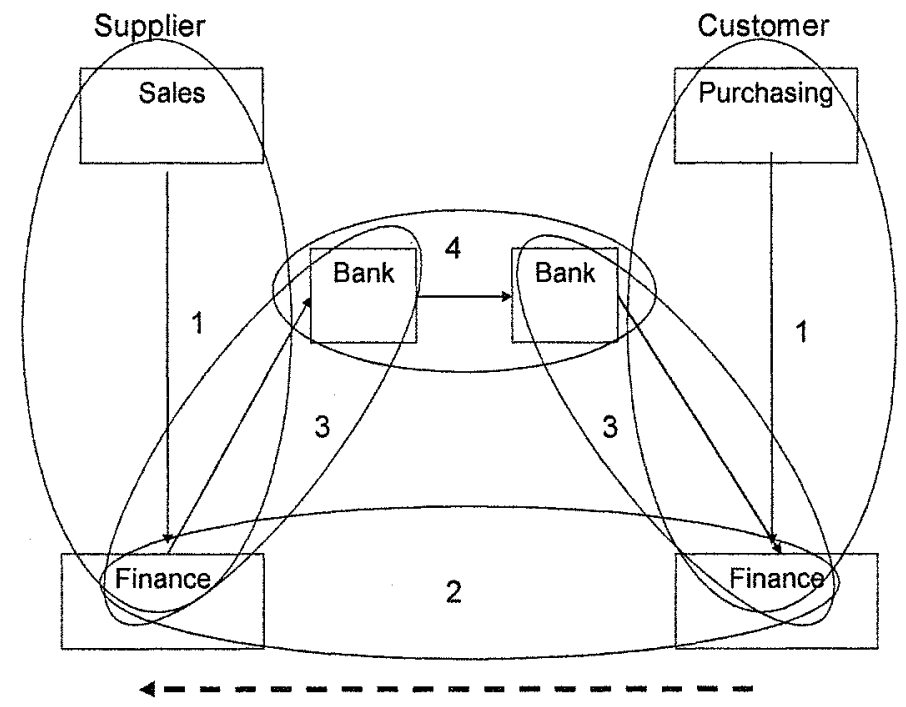

Uncertain transfer of information

Fig. 2. Uncertain transfer of information

\subsection{Purchasing/Sales and Finance Functions}

The customer's finance function will set controls on the minimum credit period that the purchasing manager can agree. With international transactions the finance function will encourage the purchasing and sales managers to negotiate a price in their own currency to remove the risk of adverse movements in foreign exchange. 
While the finance function can automate the transfer of information with the purchasing and sales functions, they do not act on the information with certainty, and can delay payments to suppliers to match the expected flow of cash into the business [8].

\subsection{Finance Functions}

Due to the uncertainty of the movement of funds, the relationship between the finance functions of the trading partners is adversarial, illustrated by methods to optimise the cost of orders by delaying payment $[9,10]$

\subsection{Banks}

The process of transferring funds through the banking system often lacks transparency. The use of cheques introduces delays due to the postage system and time to process the cheque [11]. International payments are frequently delayed by up to ten days by the banks involved in transferring the funds [12]

\subsection{Bank and Finance Function}

The supplier receiving the funds is forced to react to information provided by their bank concerning the receipt of funds, rather than rely on certain information from their customer. Trading foreign exchange is an adversarial transaction. Banks do not charge a consistent margin, and it is up to the corporation to monitor the market price and obtain multiple offers of prices to achieve the best price. Companies that are not large enough to obtain multiple prices direct from the bank trading rooms are compelled to accept less competitive pricing.

\section{Implications of Time Delays and Uncertainty in the Financial Supply Chain}

The costs generated by time delays and uncertainty in the financial supply chain can be broken down into three main areas: administrative costs; working capital and foreign exchange costs. Each of these is described in turn. 


\subsection{Administrative Costs}

The adversarial nature of relationships in the financial supply chain results in considerable administrative costs due to the effort required to prompt customers to pay on time. An indication is the cost of factoring, typically used by smaller companies [7], to manage the process of collecting payments which can range from $0.75 \%$ to $2.5 \%$ of the value of the invoice (UK Department of Trade and Industry 2005 ).

\subsection{Working Capital}

The lack of certainty within the financial supply chain results in the trading partners retaining excess balances with their banks. The value of excess balances or cash stocks held by the Fortune 1000 companies has been estimated as $\$ 90$ billion [8]. The key issue with holding surplus cash for smaller companies is that it may use a portion of the limited amount of capital available to fund the development of the company. Credit terms in the UK and US are typically 30 days $[6,11$, and 7$]$ but collection times in the UK are typically between 45 and 60 days [7]. Holding two weeks of surplus cash, to compensate for delayed payments, for a company with a cost of capital of $10 \%$ equates to an additional cost of $0.8 \%$. In the UK companies are legally entitled to charge interest of $8 \%$ above the base rate for late payments. In practice only $3 \%$ regularly implement the interest charges due to the potential adverse effect on sales [7]

\subsection{Foreign Exchange}

Small to medium sized enterprises (SMEs) typically have a higher cost for converting foreign exchange than large companies. The typical cost of converting currency for SMEs in the US has been quoted as $0.5 \%$ to $2.5 \%$ [14] while multinational companies can exchange currency for less than $0.05 \%$. Foreign exchange rates are continuously fluctuating which can result in a significant variation between the foreign exchange rate at the time a price is agreed and when the payment is made. The amount and mix of foreign currencies outstanding for a company will vary considerably. To illustrate the issue, the company in the model is assumed to have a mix of currency contracts, which match the distribution for total UK exports for 2004 (UK Customs and Excise). The average delay between a contract being agreed and settled is assumed to be three months (Figure 3), consisting of forty five days to fulfil the order and forty five days to receive the payment. 
The Management of Financial Supply Chains: From Adversarial to Co-operative Strategies 87

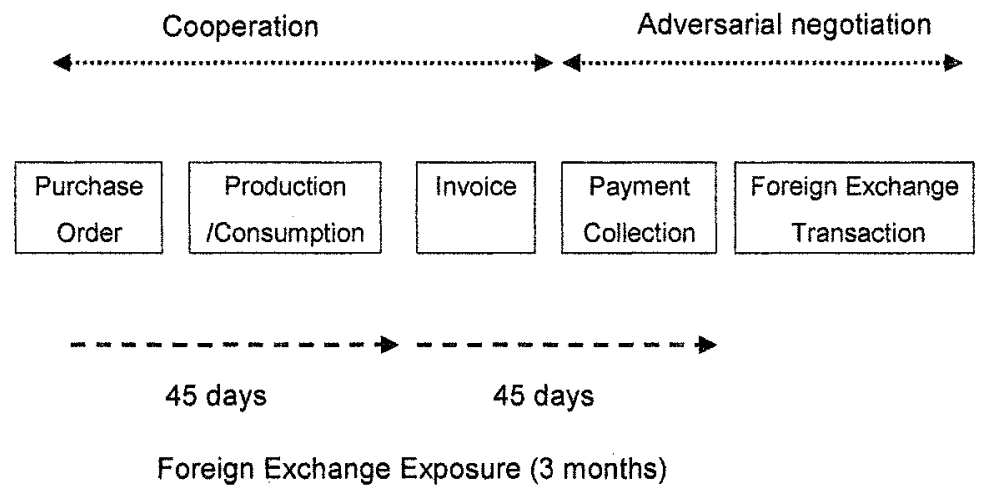

Fig. 3. Time the foreign exchange risk is retained by the supplier

Taking the exchange rate for each currency at the end of each month, over a three month period, the variation in the foreign exchange losses and gains can be estimated (Figure 4). 


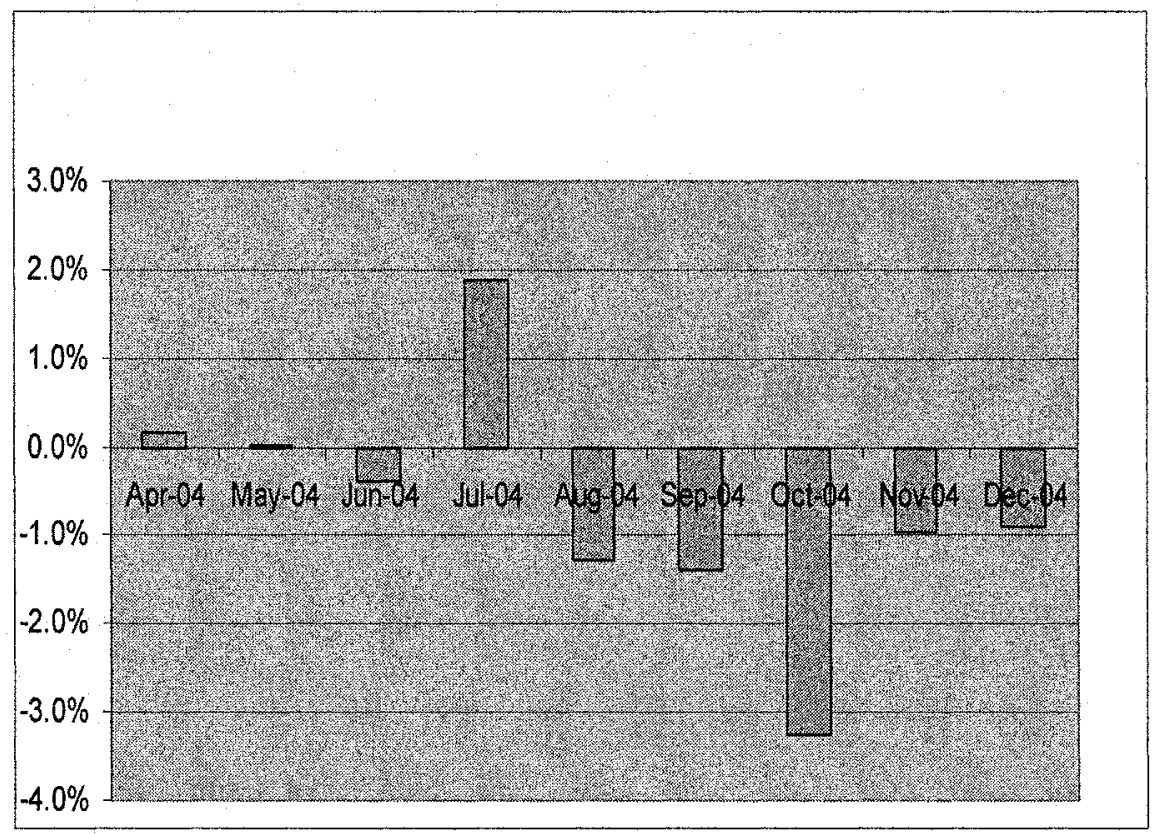

Fig. 4. Illustration of Foreign Exchange Losses and Gains for a UK Company

In the example there is a reasonable level of uncertainty of the value of foreign exchange losses and gains for each month which varies between $+1.8 \%$ and $-3.2 \%$. The figures above are for the average of all the foreign payments and receipts in a month. The range of actual gains and losses for individual transactions would be greater. Empirical studies have shown that smaller companies are less likely to implement a hedging strategy due the high fixed operating costs [15]. To reduce the impact of potential foreign exchange losses on a contract, it is assumed that the smaller supplier would add $1.5 \%$ to the price of the order. The conservative estimates suggest that the costs incurred within the financial supply chain due to the adversarial relationships are significant.

Administrative cost $1.0 \%$

Surplus balances ( 2 weeks) $\quad 0.8 \%$

Foreign exchange $\quad 0.5 \%$

Uncertainty of rate of foreign exchange $\underline{1.5 \%}$

Total

$\underline{3.8 \%}$

The total savings across a supply chain can be significant. The implications of the adoption of a cooperative financial supply chain on the financial performance of international trade for a country can be estimated using data from the World Trade Association. The total value of international trade with the UK for 2004 was $£ 1,148$ billion. A conservative estimate is that $30 \%$ of international financial transactions are adversarial. Therefore there is a potential supply chain saving to the UK of approximately $£ 13$ billion. 
An area for future research is to determine the trading partners' perception of the financial transaction costs, the actual value of the transaction costs and the typical margin added to the supplier's prices to account for the lack of certainty. One of the few documented examples of a cooperative financial supply chain is Motorola, which integrated its accounts payable function with its central finance function to centralise the corporation's purchase of international payments and foreign exchange [16]. The integration of the accounts payable and foreign exchange systems ensured all of the international transactions could be managed by the central finance function. Their bank, Citibank, provided a certain time frame for their suppliers to receive the international payments. The suppliers were notified in advance electronically of the date their bank would receive the funds. Motorola was able to reduce the costs within its financial supply chain by managing the conversion of the foreign exchange and providing a certain date of payment.

\subsection{The Transition to Co-operative Supply Chains}

An adversarial relationship can benefit the customer in terms of delaying the payment and stipulating that the transaction is carried out in the customer's preferred currency. However, if the supplier is aware of the extra costs associated with delayed cash flow and foreign exchange transactions, then it should be possible for the customer to negotiate better prices in exchange for prompt payment terms and a shared approach to managing the foreign exchange transaction. For example a large European customer could agree to pay a small U.S. supplier in dollars on the basis that the large customer can deal with the foreign exchange risk more efficiently than the small U.S. supplier. If this is coupled with certainty of payment terms then the supplier is able to plan accurately for cash flow management and can make more efficient use of limited capital. The customer's finance function will need to have a fully integrated process between the finance and purchasing function and its bank to ensure the payment is made on the agreed date. The finance function would also need to be integrated with its purchasing function and bank to minimise the delay between accepting a foreign exchange exposure when agreeing a contract and hedging the exposure.

There is the potential for the finance department to integrate the foreign exchange trading capability with the pricing system of the purchasing department, to assist the negotiation of prices in foreign currency and to immediately hedge a transaction with its bank when a purchase order is issued. Finance departments within large companies are already executing a significant portion of their foreign exchange transactions with their bank partners electronically [17] and the services are being rapidly adopted [18]. The automated trading of foreign exchange removes the transaction costs that limit manual trading to large transaction values. To automatically trade the foreign currency for individual purchase orders the bank will need to move to contractual agreements where it states the margin that they will charge, removing the adversarial nature of the relationship and the requirement for the corporation to continuously obtain several competitive prices for each trade. 
In essence a cooperative financial supply chain requires a different way of thinking from the finance function within the trading partners in a supply chain, especially that of the major one. However in information terms the problem is straight forward, compared to that of handling vast amounts of manufacturing data. Similarly this way of thinking is already in operation within the manufacturing component of supply chains where partners work collaboratively to reduce costs and improve the efficiency and flexibility of manufacturing processes throughout the supply chain.

\subsection{The Implementation Options for Achieving an Integrated Financial Supply Chain}

The enterprise resource planning systems (ERP) of large companies already integrate the information systems between the purchasing, sales and finance functions. These applications allow large companies to collect information on the foreign exchange risk generated, from the entry of purchase orders and invoices. This allows the company to hedge the foreign exchange exposure shortly after it is generated, but does not enable the purchasing and sales functions to determine when there is real financial benefit in generating the exposure. To enable the large companies to exploit their twin advantages of sophisticated information systems and the ability to manage risk, the sales and purchasing functions should be supplied with real time information on the foreign exchange rates that are available to the company to hedge the risk. The sales and purchasing functions can then determine whether the most profitable pricing is in their own currency or their trading partner's.

Large companies are able to use their integrated information systems to ensure that invoices are processed and paid on time. This is more likely to be implemented as a standard means of operation rather than on an ad hock basis. It is technically possible to electronically hedge the foreign exposure of each purchase order with a bank. An automated system removes the capacity restraints of the bank's dealing room and provides the opportunity for the bank to charge the large company for the gross amount of foreign exchange converted.

\subsection{Barriers to implementing a co-operative financial supply chain}

The technology to implement the proposed solution is already available and is not a barrier to implementation. The key barriers are organisational as the role and relationships between the different functions and organisations will change. With the implementation of JIT time techniques the reduction in working capital was a direct benefit to the large customer. With the changes in the financial supply chain the larger company incurs an additional cost and is required to negotiate a discount from its trading partner that captures a portion of the benefits. Before a supplier is willing to offer a discount it will need to trust the customer to provide the increased financial certainty. The customer may need to provide the altruistic act of demonstrating it can deliver the benefits before the supplier would be willing to provide an additional discount. The supplier may be working with fine margins with the key customer. The cost of payment delays, uncertainty and foreign exchange losses are incurred 
after the sale and may not influence the initial negotiations. The supplier's finance and sales functions will need to be able to cooperate to determine the potential costs, incurred at a transaction level, before there is a perceived benefit from the increase in financial certainty.

The change in the responsibilities and working practises of the finance functions is significant and is likely to face organisational resistance. There is considerable resistance to changes in a process where it moves responsibilities between functions [20]. The customer will need to accept and manage foreign exchange risk on a real time rather than a periodic basis and will loose the ability to manage their cash flow position by manipulating supplier payments. The movement to electronically trading small amounts of foreign exchange at the level of purchase orders and charging on the basis of the gross amount of funds converted would remove the banks ability to opportunistically price foreign exchange transactions. This would diminish the role of the bank's customer traders, which seek opportunities to widen the bank's margin for trading individual foreign exchange transactions.

An implementation of a cooperative financial supply chain will take time to overcome each of the organisational barriers. Leadership from the senior management within the customer's company will be required to initiate the initial changes in the roles of the purchasing and finance functions. Trust will also need to be built with the finance function of the supplier. The banks will need to recognise the operational benefits of automating the foreign exchange trading process. An incremental implementation will be required for the customer's finance function to adapt to the operational requirements of the process and to accept the reduction in financial flexibility. The financial benefits are potentially significant and the early adopters that invest in overcoming the organisational barriers to building a cooperative financial supply chain should achieve a comparative advantage over competing supply chains.

\section{Implications of the movement to a cooperative financial supply chain}

The movement to a cooperative financial supply chain reduces the costs incurred within the overall supply chain. The purchase of the financial services is moved to the trading partner with the lowest cost of purchase that should also be able to negotiate the bulk of the financial benefits. There is the potential for producers of scarce components/services to dedicate a larger portion of their production to the supply chain that can provide financial certainty. The key beneficiary is the complete supply chain that is able to deliver the end product/service to meet developing market needs at a lower cost. The supply chains that take steps to implement the cooperative financial process are likely to build a significant comparative advantage compared with their competition due to the time required to respond. 
Significant investment in information systems is required by the banks to be able to automate the financial process to deliver the financial services at an acceptable cost and quality. The leading global banks have already made this investment which provides them with the opportunity to build significant scale benefits. It will take time to build the trust required between the finance function and their key bank. The banks that can incrementally implement the changes in cooperation with their key customers should build a significant advantage. The implications for the banking industry are readily apparent. The bank providing the automated services to the largest trading partner will lower its costs of distribution to the supply chains smaller trading partners (Figure 5).

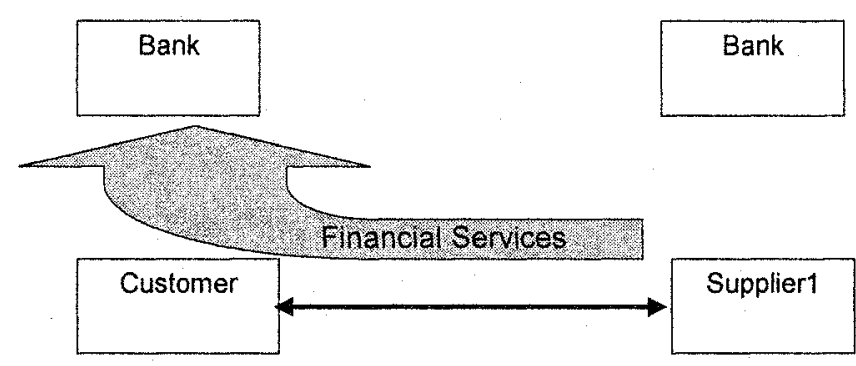

Certain transfer of information

Fig. 5. Company with the lowest cost of banking services consolidates purchases

There is already an increase in the consolidation of the financial service industry and the developments proposed and discussed in this paper will accelerate the process as financial institutions focus on reducing their cost ratios to maintain their financial performance [20]. It is very likely that as organisations strive, under ever-fiercer competition, to make their supply chains even more efficient they will focus on the financial arrangements. Almost certainly there will be a move to make the financial flows mirror product flows, and the various operational and financial systems will come into line. The financial aspects of the supply chains will have to become transparent and much more detailed information will be required. This will enable the financial aspects of the supply chain to be managed as one entity rather than a set of disparate unrelated financial transactions. It will allow for the purchasing power of 
the largest trading partner to be used to the mutual benefit of the whole supply chain thus making it even more efficient. For banks it will lead to an overall reduction in income, particularly for the smaller players. The banks who can work with supply chains and who are willing to work for greater efficiency will have the potential to develop new markets at the expense of some of their slower competitors. The whole banking industry will be affected by the concepts discussed in this paper which are now ready for implementation and wide scale adoption.

\section{Discussion and Conclusions}

The paper has extended the concept of JIT for production systems to the provision of financial services in the supply chain. It has demonstrated using case examples how major savings can be made by reducing the time delays in financial supply chains and by co-operation between organisations involved in successive stages of the supply chain, in particular to exploit the trading and negotiation power of large organisations. The IT capability is already in place in the form of enterprise and ecommerce systems and will require only modest enhancements. The pace of change will be determined by the ability of companies to change their internal organisational processes and relationships. The alignment of financial information flows with those of physical transactions is a logical development in supply chain arrangements and will play an important part in their increasing impact on business operations. As there is even more pressure from competition to reduce the costs of supplying product, the financial flows will need to become more transparent and management will focus on the purchase and delivery of financial services in a similar way that they currently do on supply chain operation. Both engineering and manufacturing are now done on a co-operative basis and it is only a matter of time before the same approaches are applied to finance and accounting. The increased certainty and removal of adversarial relationships between the finance functions should increase the trust and deepen the relationship between the trading partners. The early adopters should gain an advantage in the strength of key trading relationships that will take their competitors time to replicate. Given the present supply chain arrangements and future industrial trends, i.e. that of making strong alliances, much more attention will be given to the problem in the next decade. Organisations will reduce their costs of financing their supply chains and make them become even more integrated.

The implications for banks are readily apparent with a reduction of income overall from this activity. Global banks that are prepared to innovate and work with supply chains rather than just the separate partners may benefit from a much larger share of the market even though the unit profitability is lower. The banks who are first into the field may gain significant benefits and have very little to loose. The developments in inter organisational systems enable virtual organisations to be easily created and managed as a single entity, and information systems are the enablers of such major change. There is the potential for the dramatic growth of financial institutions that have integrated their own systems to remove capacity restraints and 
that are willing to work with key relationship customers and price competitively to increase their market share. The highly integrated financial service companies with strong relationships with the most powerful organisations in each supply chain can dramatically reduce their effective cost of distribution by using their key clients as the intermediary to access the other supply chain organisations. The financial efficiency of an integrated virtual supply chain should match the efficiency of a vertically integrated company where the finance function is centralised and integrated with the core functions of the company.

\section{References}

1 T. Davis, Effective Supply Chain Management, Sloan management review 34(4), 35-46 (1993).

2. H. L. Lee and C. Billington, Managing Supply Chain Inventory: Pitfalls and Opportunities, Sloan Management Review 33(3), 65-73 (1992).

3. T. Mukhopadhyay, S., Kekre and S. Kalathur, Business value of information technology: A study of electronic data interchange, MIS Quarterly 19(2), 137 (1995).

4. M. Subramani, How do Suppliers Benefit from Information Technology use in Supply Chain Relationships? MIS Quarterly 28(1), 45-73 (2004).

5. C. Holland, G. Lockett and I. Blackman, Planning for Electronic Data Interchange, Strategic Management Journal 13 (7), 539-550 (1992).

6. C. K. Ng, J.K. Smith and R. L. Smith, Evidence on the determinants of credit terms used in interfirm trade, Journal of Finance 54(3), 1109 (1999).

7. R. Pike and Nam Sang Cheng, Credit Management: An Examination of Policy Choices, Practices and Late Payment in UK Companies, Journal of Business Finance \& Accounting 28(7/8), 1013-1042 (2001).

8. J. Abolins, Emergence of the Financial Supply Chain, Treasury Management International 125, 5 (2004).

9. Chun-Tao Chang and Shuo-Jye Wu, A note on optimal payment time under permissible delay in payment for products with deterioration, Production Planning \& Control 14(5), 478 (2003).

10. B. R. Sarker, A. M. M. Jamal and S. Wang, Optimal payment time under permissible delay in payment for products with deterioration, Production Planning \& Control 11(4), 380-390 (2000). 
11. P. Naude, G. Lockett and I. Blackman, Evaluating a financial service opportunity via judgemental modelling, International Journal of Service Industry Management 4(4), 25-41 (1993).

12. Stick beats carrot, Economist 378(8463), 67-68 (2006).

13. R. Pike, Nam Sang Cheng, K. Cravens and D. Lamminmaki, Trade Credit Terms: Asymmetric Information and Price Discrimination Evidence From Three Continents, Journal of Business Finance \& Accounting 32(5/6), 1197-1236 (2005).

14. D. S. Levine, Making sense of dollars, World Trade 11(8), 74 (1998).

15. M. Glaum, The determinants of selective exchange risk management-Evidence from German corporations, Journal of Applied Corporate Finance 14(4), 108-121 (2002).

16. C. P. Holland, G. Lockett and I. D. Blackman, The Evolution of a Global Cash Management System, Sloan Management Review 36(1), 37-47 (1994).

17. J. Beckert, Is the price right? FX-MM May, 24-25 (2004).

18. J. Hughs, Currency Trading Volumes Double Online, Financial Times, $\left(10^{\text {th }}\right.$ Jan 2005), 20 .

19. R. Nelson and S. G. Winter, An Evolutionary Theory of Economic Change, (Harvard University Press, Cambridge, MA, 1982).

20. C. P. Holland, A. G. Lockett and I. D. Blackman, Global strategies to overcome the spiral of decline in universal bank markets, The Journal of Strategic Information Systems 7(3), 217-232 (1998). 